\title{
The Influence of Diapycnal Mixing on Quasi-Steady Overturning States in the Indian Ocean
}

\author{
Matthew D. Palmer \\ National Oceanography Centre, Southampton, Southampton, and Hadley Centre for Climate Prediction and Research, \\ Exeter, United Kingdom \\ Alberto C. Naveira Garabato \\ National Oceanography Centre, Southampton, Southampton, United Kingdom \\ JOHN D. STARK \\ Hadley Centre for Climate Prediction and Research, Exeter, United Kingdom \\ JOËL J.-M. HIRSCHI \\ National Oceanography Centre, Southampton, Southampton, United Kingdom \\ Jochem MAROTZKe \\ Max Planck Institute for Meteorology, Hamburg, Germany
}

(Manuscript received 14 March 2006, in final form 27 December 2006)

\begin{abstract}
A regional general circulation model (GCM) of the Indian Ocean is used to investigate the influence of prescribed diapycnal diffusivity $\left(K_{d}\right)$ on quasi-steady states of the meridional overturning circulation (MOC). The model has open boundaries at $35^{\circ} \mathrm{S}$ and $123^{\circ} \mathrm{E}$ where velocity, temperature, and salinity are prescribed at each time step. The results suggest that quasi-steady overturning states in the Indian Ocean are reached on centennial time scales. The size and structure of the MOC are controlled by the distribution of $K_{d}$ and the southern boundary conditions. The distribution of $K_{d}$ required to support an overturning circulation in the model interior of a magnitude equal to that prescribed at the southern boundary is estimated using a 1D advection-diffusion balance in isopycnal layers. Implementing this approach, $70 \%-$ $90 \%$ of the prescribed deep inflow can be supported in quasi-steady state. Thus one is able to address the systematic discrepancy between past estimates of the deep MOC based on hydrographic sections and those based on GCM results. However, the $K_{d}$ values required to support a substantial MOC in the model are much larger than current observation-based estimates, particularly for the upper $3000 \mathrm{~m}$. The two estimates of the flow field near $32^{\circ} \mathrm{S}$ used to force the southern boundary imply a highly nonuniform distribution of $K_{d}$, as do recent estimates of $K_{d}$ based on hydrographic observations. This work highlights the need to improve and implement realistic estimates of (nonuniform) $K_{d}$ in ocean and coupled ocean-atmosphere GCMs when investigating quasi-equilibrium model states.
\end{abstract}

\section{Introduction}

The deep overturning of the Indian Ocean is a fundamental component of the global circulation. Deep waters, which originate from the North Atlantic Ocean

Corresponding author address: Matthew Palmer, Hadley Centre for Climate Prediction and Research, Met Office, FitzRoy Road, Exeter, Devon EX1 3PB, United Kingdom.

E-mail: matthew.palmer@metoffice.gov.uk and the Southern Ocean, flow northward into the Indian Ocean below about 2000 m (Mantyla and Reid 1995; Reid 2003). These waters are mixed, become less dense, and return south to exit the Indian Ocean above $2000 \mathrm{~m}$. Both the magnitude and the vertical structure of the resulting deep meridional overturning circulation (MOC) are a source of controversy in the existing literature. In particular there has been poor agreement between estimates based on hydrographic sections and those using general circulation models (GCMs).

DOI: $10.1175 / \mathrm{JPO} 3117.1$ 
Toole and Warren (1993) used a hydrographic section at $32^{\circ} \mathrm{S}$ and water properties to determine a deep MOC of $27 \pm 10 \mathrm{~Sv}\left(\mathrm{~Sv} \equiv 10^{6} \mathrm{~m}^{3} \mathrm{~s}^{-1}\right)$. Robbins and Toole (1997) realized that this flow field violated the silica budget and added silica conservation as a constraint. Through an inverse calculation they obtained a smaller MOC of $12 \pm 3 \mathrm{~Sv}$. Subsequent inverse studies, using the same 1987 section, by Ganachaud et al. (2000) and Sloyan and Rintoul (2001) estimated the MOC as $11 \pm 3$ and $23 \pm 3 \mathrm{~Sv}$, respectively. Bryden and Beal (2001) showed that the size of the MOC was sensitive to the strength of the Agulhas Current. Using acoustic Doppler current profiler measurements in the Agulhas Current to reference a geostrophic flow field they estimated an MOC of $10 \mathrm{~Sv}$.

In contrast to the studies discussed above, global (e.g., Garternicht and Schott 1997; Stammer et al. 2003) and regional (e.g., Lee and Marotzke 1997; Lee and Marotzke 1998; Zhang and Marotzke 1999) ocean GCMs have shown a deep MOC of only a few Sverdrups. The exception is the work of Ferron and Marotzke (2003; hereinafter FM) who invoked an 18-Sv overturning in a regional model of the Indian Ocean. This result was achieved by constraining the model interior to match (within the estimated errors) hydrographic observations made in 1995 as part of the World Ocean Circulation Experiment (WOCE).

Recent observational estimates of $K_{d}$ in the ocean (e.g., Polzin et al. 1997; Naveira Garabato et al. 2004) have shown locally enhanced values far exceeding the canonical value of $10^{-4} \mathrm{~m}^{2} \mathrm{~s}^{-1}$ (Munk 1966; Munk and Wunsch 1998), which has traditionally been adopted in GCMs. Enhanced $K_{d}$ is often associated with the breaking of internal waves generated as flows (e.g., barotropic tidal currents) encounter rough topography (e.g., Ledwell et al. 2000), although other mechanisms involving complex bathymetry have been suggested as dominant (Bryden and Nurser 2003; Thurnherr et al. 2005). Given the amount of rough topography of the Indian Ocean one might anticipate large mixing rates in the region and a correspondingly large MOC (e.g., Toole and Warren 1993). Hasumi and Suginohara (1999) investigated the effects of enhanced vertical diffusivities over rough topography in a global GCM. They found the $3 \mathrm{D}$ circulation to be sensitive to the distribution of vertical mixing.

In this paper we revisit the work of FM. Although FM were successful in showing the presence of a strong deep overturning in a regional model of the Indian Ocean, there are limitations to their work. First, the forward part of the run under the optimized forcings was only integrated for 1 year, so little is known about the long-term stability of the solution. Second, FM used horizontal and vertical mixing rather than the preferred eddy parameterization and isopycnal mixing of a GentMcWilliams (GM)-Redi scheme (Redi 1982; Gent and McWilliams 1990; see Griffies et al. 1998 for a review), which detracts somewhat from their findings. The GMRedi scheme improves the representation of boundary currents (e.g., Danabasoglu et al. 1994), which are an important component of the Indian Ocean deep MOC, and reduces the spurious diapycnal mixing that occurs in areas of sloping isopycnals under a horizontal/vertical mixing parameterization. To address these limitations we extend the forward run of the FM solution to 200 years using a GM-Redi scheme and investigate the evolution of the overturning streamfunction. In subsequent model experiments, we use an observation-based estimate of the distribution of the diapycnal mixing rate (expressed as a diapycnal diffusivity, $K_{d}$ ) and also diagnose the $K_{d}$ field required to sustain the FM solution indefinitely, using the approximation of a 1D advection-diffusion balance. In a final model experiment we apply diagnosed $K_{d}$ to a model forced with the Ganachaud (2003, hereinafter G03) estimate of the flow field across $32^{\circ} \mathrm{S}$. The primary aim of this work is to establish whether, and how, a large MOC can be supported in a regional GCM of the Indian Ocean in a quasi-steady state.

\section{Estimates of diapycnal diffusivity from CTD/LADCP observations}

We use estimates of $K_{d}$, obtained by applying an internal wave-wave interaction model to observations of density fine structure from conductivity-temperaturedepth (CTD) data and velocity fine structure from lowered acoustic Doppler current profiler (LADCP) measurements following Naveira Garabato et al. (2005; see also Kunze et al. 2006). The data come from WOCE hydrographic sections occupied in 1995: I01 at $10^{\circ} \mathrm{N}$ [I01W stations 901-933, 935, and 939-956, and I01E stations 971-1004 and 1008-1013 (Shi et al. 2002)], I02 at $10^{\circ} \mathrm{S}$ [stations $1077-1105,113-114,1127-1156$, and 1167-1227 (Johnson et al. 1998; Warren and Johnson 2002)], and a crossing of the Indian Ocean at $32^{\circ} \mathrm{S}$ in 2002 (Bryden 2003), CD139 (Fig. 1). In a crude attempt to capture the broad spatial distribution of diapycnal mixing in the Indian Ocean, we take the zonal mean of each of the three sections and then interpolate the data onto the model levels using an area-weighted mean to conserve the depth-integrated value for $K_{d}$ (Fig. 2). We then apply a simple 2D linear interpolation between the three zonal mean $K_{d}$ profiles to arrive at a mixing field that is a function of depth and latitude (Fig. 3). Although the three sections are evenly spaced the data 

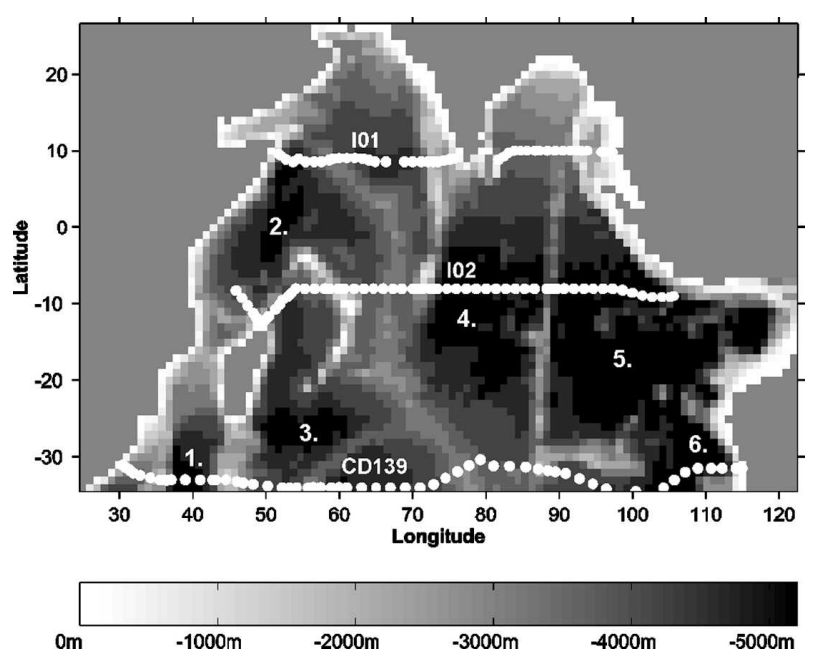

FIG. 1. Station locations of hydrographic data used to construct the observational estimate of turbulent diapycnal mixing. The bathymetry shown is that of the GCM used in this investigation. The following deep basins have been marked-1: Mozambique Basin; 2: Somali Basin; 3: Madagascar Basin; 4: central Indian basin; 5: West Australian Basin; 6: Perth Basin.

coverage is limited. Therefore, there could be significant biases in our values of $K_{d}$ associated with the observational sampling. A second source of error comes from the interpolation of hydrographic data onto the model grid (see the appendix), though this is likely to be small relative to the sampling bias. The representation of $K_{d}$ as a zonal average eliminates many of the mixing "hotspots" inferred from the hydrographic section data (e.g., Naveira Garabato et al. 2005) and raises the overall background $K_{d}$ relative to the observations.

\section{Estimates of diapycnal diffusivity from 1D advection-diffusion balance}

In this section we describe a method to estimate the Indian Ocean mean $K_{d}$ profile required to support a given MOC regime in a steady state. Under the approximation of a steady state and a $1 \mathrm{D}$ advection-diffusion balance, the combined density and velocity field at the southern boundary of the Indian Ocean has an implied diapycnal mixing distribution. The 1D advectiondiffusion approach relies on the assumption that the regional variability of the buoyancy frequency $(N)$ is small on deep isopycnals and not significantly correlated with spatial variability in $K_{d}$. In reality, we observe some variability in buoyancy frequency at deep levels (not shown), which is likely nonnegligible. However, the correlation between $K_{d}$ and $K_{d} N^{2}$ seen in the LADCP data suggests that variability of $N$ does not dominate the overturning forcing term (Naveira Gara-

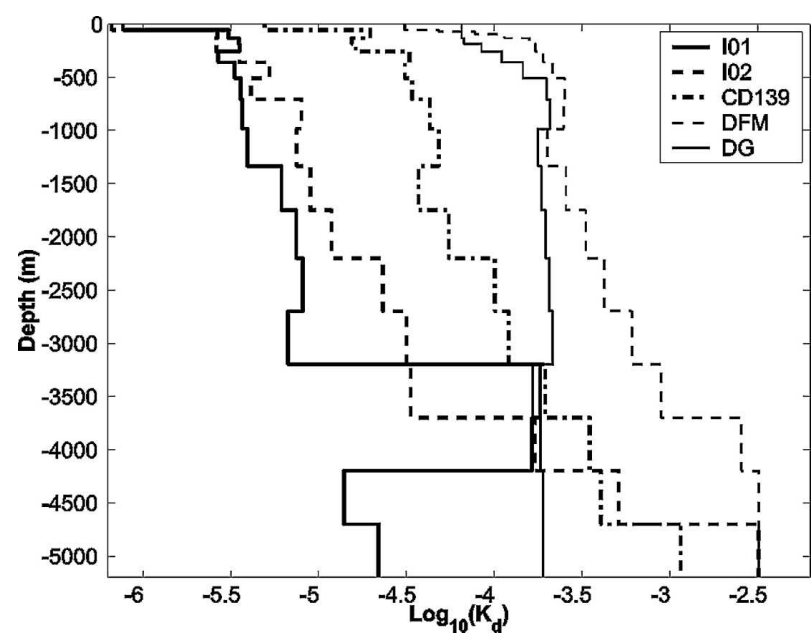

FIG. 2. Zonal-mean $K_{d}$ profiles $\left(\mathrm{m}^{2} \mathrm{~s}^{-1}\right)$ for each hydrographic section (I01, I02, CD139) and the $K_{d}$ profiles diagnosed from the FM and G03 solutions (DFM and DG).

bato et al. 2005). This approach is possible in the Indian Ocean because there is no deep convection (such as in the North Atlantic and Mediterranean Sea). The 1D approximation does not hold in the mixed layer.

In the schematic of the zonal mean flow field and isopycnals in the Indian Ocean (Fig. 4), $\rho_{n}$ is mean potential density of layer $n, \rho_{n(n+1)}$ is potential density of interface between layers $n$ and $n+1$, and $T_{n}$ is advective transport into layer $n$. The turbulent mass transport across the interface between layers $n$ and $n+1$ is given by

$$
F_{n(n+1)}=-K_{d} \frac{\partial \rho}{\partial z} A_{n(n+1)},
$$

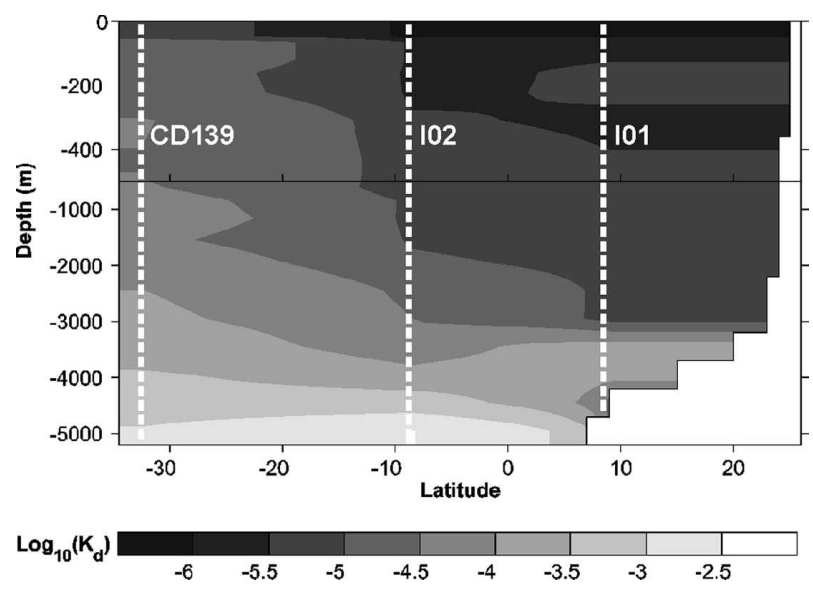

FIG. 3. Two-dimensional diapycnal diffusivity $\left(K_{d}\right)$ field based on the observations $\left(\mathrm{m}^{2} \mathrm{~s}^{-1}\right)$. The meridional locations of the hydrographic sections are indicated by the white dashed lines. 


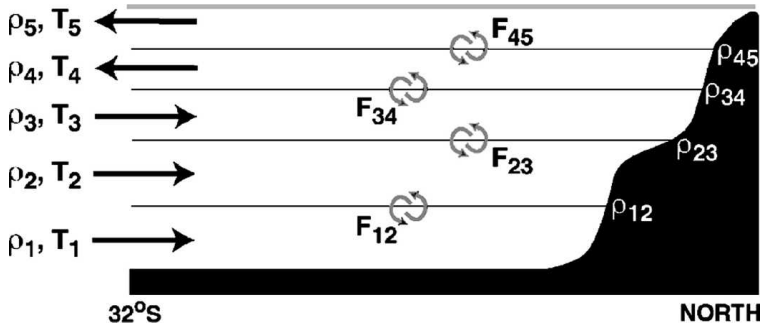

FIG. 4. A schematic example of the zonally integrated flow field in the Indian Ocean interior, broken down into five isopycnal layers.

where $K_{d}$ is the local diapycnal diffusivity, $\partial \rho / \partial z$ is the density gradient across the interface, and $A_{n(n+1)}$ is the area of the interface.

For layer $n$, conservation of mass in a steady state dictates that the net advection of mass into each layer must equal the net turbulent diffusion out of the layer:

$$
\begin{gathered}
\left(\rho_{n}-\rho_{n(n+1)}\right) T_{n}+\left(\rho_{(n-1) n}-\rho_{n(n+1)}\right) \sum_{i=1:(n-1)} T_{i}= \\
F_{n(n+1)}-F_{(n-1) n} .
\end{gathered}
$$

The density field and velocity field (and therefore $T_{n}$ and $\partial \rho / \partial z$ ) are prescribed at the model southern boundary, so these fields are steady state by definition. The velocity fields used are from FM and G03. Both are absolute velocity fields that were estimated using inverse methods and include the Indonesian Throughflow (IT) transport. The density fields come from FM and hydrographic data from the 1987 crossing of the Indian Ocean at $32^{\circ} \mathrm{S}$ (Toole and Warren 1993). We obtain the area of each density interface $\left[A_{n(n+1)}\right]$ using the WOCE Global Hydrographic Climatology (Gouretski and Koltermann 2004) and arrive at a $1 \mathrm{D}$ profile for $K_{d}$ (Fig. 2), which is a function of density interface. This 1D profile is converted to a depth profile using mean layer depths and applied to the entire model interior. We expect the error associated with the transformation of $K_{d}$ from isopycnals to vertical levels to be small since the horizontal density gradients in the ocean interior are generally small.

\section{Model configuration}

We use the Massachusetts Institute of Technology (MIT) ocean general circulation model (Marshall et al. $1997 \mathrm{a}, \mathrm{b})$ configured for the Indian Ocean. Our model domain extends from $\left(35^{\circ} \mathrm{S}, 24^{\circ} \mathrm{E}\right)$ to $\left(26^{\circ} \mathrm{N}, 123^{\circ} \mathrm{E}\right)$ with open boundaries at $123^{\circ} \mathrm{E}$ for the IT and at $35^{\circ} \mathrm{S}$ for the Southern Ocean (Fig. 1). The horizontal resolution is $1^{\circ}$ and there are 22 vertical levels (10-m resolution near the surface down to $500 \mathrm{~m}$ for the deepest six levels). The model bathymetry is interpolated from the 5-minute gridded elevations/bathymetry for the world data (ETOPO5) 1998 data. Isopycnal and diapycnal mixing processes in the model are parameterized using a GM/Redi scheme and a convection algorithm, respectively. At the open boundaries potential temperature $(\theta)$, salinity $(S)$, and velocity $(v)$ normal to the boundary are prescribed at each time step. The combination of these prescribed fields directly determines the amount of heat and freshwater that enter and leave the model domain via the open boundaries, and the fluxes are independent of the model interior evolution. As a result, some model drift of basin-integrated heat and freshwater content is inevitable. However, the advantage of these open boundary conditions is that the deep MOC at the southern boundary can be prescribed. This is not possible in a conventional global GCM. The model initial conditions for $\theta, S$, and horizontal velocity originate from a 10-yr spinup of the model under restoring to World Ocean Atlas 1994 (WOA94) (Levitus and Boyer 1994; Levitus et al. 1994) temperature and salinity for the upper 12 model levels $(710 \mathrm{~m})$. The mean state of year 10 of the model spinup served as "first guess" initial conditions and wwere subsequently modified by the FM adjoint procedure. It is noted that deep western boundary currents are not well represented in WOA94 and may have suppressed the MOC in the FM initial conditions.

The model surface is forced with daily heat and freshwater fluxes and twice-daily wind stresses, which were modified from the National Centers for Environmental Prediction (NCEP) 1995 values (Kalnay et al. 1996) by the FM adjoint procedure. The model surface forcings are the same as those described in FM, but with the addition of a 30-day restoring to sea surface temperature and salinity from WOA94. For the final model experiment, the FM southern boundary conditions are replaced by the hydrographic section of Toole and Warren (1993) and the flow field across $32^{\circ} \mathrm{S}$ from G03 (see section $5 \mathrm{~b}$ for details). The G03 flow field requires an increase in the IT strength from the $10 \mathrm{~Sv}$ used by FM to $16 \mathrm{~Sv}$. This is achieved by applying an additional spatially uniform velocity at the eastern open boundary in order to minimize changes necessary to the model setup. The IT is represented in the model by a single channel of $1335-\mathrm{m}$ depth. Transport is directed into the model domain (westward) throughout all seasons below $100 \mathrm{~m}$ and the greatest transport occurs below $800 \mathrm{~m}$. In the upper $100 \mathrm{~m}$ net flow is directed into (westward) or out of (eastward) the model domain, depending on season (not shown).

The relatively coarse horizontal and vertical model resolution means that the complex bathymetry of the 
TABLE 1. Southern boundary and diapycnal diffusivity configurations used in the model experiments.

\begin{tabular}{cclr}
\hline \hline Expt & Southern boundary velocity field $(v)$ & \multicolumn{1}{c}{ Diapycnal diffusivity $\left(K_{d}\right)$} & Run time $(\mathrm{yr})$ \\
\hline A & Ferron and Marotzke & Uniform $2 \times 10^{-5} \mathrm{~m}^{2} \mathrm{~s}^{-1}$ & 200 \\
B & Ferron and Marotzke & Uniform $1.2 \times 10^{-4} \mathrm{~m}^{2} \mathrm{~s}^{-1}$ & 200 \\
C & Ferron and Marotzke & 2D observational estimate, $K_{d}($ lat, $z)$ & 200 \\
D & Ferron and Marotzke & Diagnosed, $K_{d}(z)$ & 200 \\
E & Ganachaud & Diagnosed, $K_{d}(z)$ & 200 \\
\hline
\end{tabular}

Indian Ocean can only be represented approximately. Some deep passages, such as in the Southwest Indian Ridge, are not included in the model. Despite this shortcoming (which is common to state-of-the-art coupled climate models) the model is capable of an abyssal circulation in qualitative agreement with the observations (section 6a).

\section{Experiments}

We set up a series of experiments using different $K_{d}$ fields and open boundary conditions; see Table 1. Experiments A-D use the southern boundary velocity field from FM. Experiment E uses the southern boundary velocity field from G03, with slightly modified bathymetry near the southern boundary to accommodate the 1987 hydrographic data. For this reason we refer to experiments A-D as the "Ferron and Marotzke configuration" and experiment $\mathrm{E}$ as the "Ganachaud configuration."

\section{a. Diapycnal diffusivity $\left(K_{d}\right)$}

Five different $K_{d}$ fields are implemented and in each case the model is integrated for 200 years. Experiment A uses the same spatially uniform $K_{d}$ of $2 \times 10^{-5} \mathrm{~m}^{2} \mathrm{~s}^{-1}$ used by FM; experiment B uses a uniform $K_{d}$ of $1.2 \times$ $10^{-4} \mathrm{~m}^{2} \mathrm{~s}^{-1}$, which is the basin-integrated average of the observational estimate; experiment $\mathrm{C}$ has an observational estimate of the $K_{d}$ field that is a function of depth and latitude (Fig. 3); and experiments D and E use diagnosed values for $K_{d}$ that are only a function of depth (DFM and DG in Fig. 2). Note that the basinaverage $K_{d}$ of experiment $\mathrm{B}$ is very close to the Munk value of $1 \times 10^{-4} \mathrm{~m}^{2} \mathrm{~s}^{-1}$ (Munk 1966; Munk and Wunsch 1998). Experiments A-D use the southern boundary conditions of FM and experiment $\mathrm{E}$ uses the G03 estimate of the flow field and $\theta$ and $S$ properties from the 1987 hydrographic section across $32^{\circ} \mathrm{S}$ (Toole and Warren 1993).

The fine structure-based $K_{d}$ profiles that we use to prescribe the model mixing environment in experiment $\mathrm{C}$ are a subset of a database of over 1000 profiles spanning all major hydrographic and bathymetric environ- ments of the Indian Ocean (Naveira Garabato et al. 2005; see also Kunze et al. 2006). We note that this subset comprises the range of $K_{d}$ values in the entire database, so it is unlikely that its geographical distribution is limiting unless mixing is extremely localized in a few confined passages (e.g., Bryden and Nurser 2003). The $K_{d}$ profiles are derived under the assumptions that the density and velocity fine structure in CTD/LADCP profiles are signatures of internal waves and that internal wave breaking is the primary driver of diapycnal mixing in the ocean, as is widely believed (e.g., Wunsch and Ferrari 2004). However, it is possible that these assumptions fail in the close vicinity of boundaries, where some authors suggest that much of the mixing may occur (e.g., Armi 1978). Therefore, bias in our 2D observationally based estimate of $K_{d}$ may arise from limited data coverage and because our methodology does not take into account all possible sources of diapycnal mixing.

The zonal mean of the observationally estimated $K_{d}$ shows large values at depth (as high as $3 \times 10^{-3} \mathrm{~m}^{2} \mathrm{~s}^{-1}$ ) and generally much smaller values above $3000 \mathrm{~m}$ (Fig. 2). As one moves south of section I01 (Fig. 3), $K_{d}$ progressively increases over most of the water column. The increase may be due to the influence of the rough topography of the Southwest Indian Ridge and associated internal wave breaking. The FM-diagnosed mixing profile (DFM, Fig. 2) shows $K_{d}$ values that increase with depth and are much larger than the observational estimates, except at the deepest model level. The $K_{d}$ values diagnosed from the G03 flow field (DG, Fig. 2) are smaller than for FM but still substantially larger than the observations for the upper $3000 \mathrm{~m}$. In contrast to the observational estimates of $K_{d}$ and DFM, the DG profile shows no increase of $K_{d}$ with depth below $3000 \mathrm{~m}$. A direct comparison between our values of $K_{d}$ and those estimated by G03 is difficult because Ganachaud divided the Indian Ocean up into three boxes, whereas we estimate $K_{d}$ for the ocean as a whole. A further complication is that the $K_{d}$ values here are based on the flow field after transformation onto the model grid (see the appendix), which will introduce some bias in the values where there are sloping 


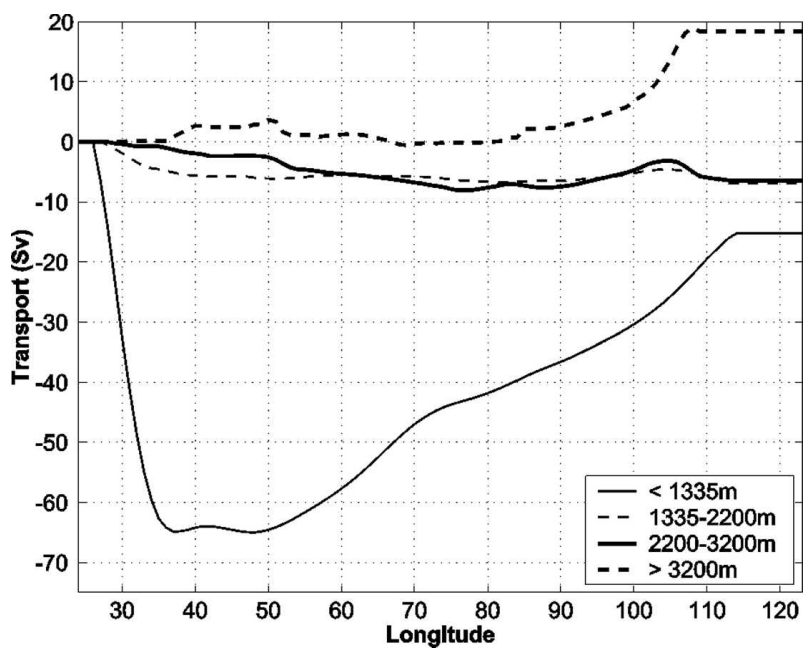

FIG. 5. The east-west cumulative transport (Sv) for the FM southern boundary conditions, broken down into four depth layers.

isopycnals. However, comparing our values to Ganachaud's subtropical box $\left(32^{\circ}-10^{\circ} \mathrm{S}\right)$, we find that for the majority of the water column our values are indistinguishable from his within his estimated errors. Ganachaud estimates a much larger $K_{d}$ of nearly $3 \times 10^{-3}$ $\mathrm{m}^{2} \mathrm{~s}^{-1}$ below $4000 \mathrm{~m}$, compared to our values of $\sim 2 \times$ $10^{-4} \mathrm{~m}^{2} \mathrm{~s}^{-1}$. However, the two values are well within the estimated error.

\section{b. Southern boundary conditions}

The origins of the FM southern boundary conditions are the WOA94 and a $2^{\circ} \times 2^{\circ}$ global ocean model (Stammer et al. 1997). The resulting optimized $\theta, S$, and $v$ fields vary smoothly in space and are time dependent. The size of the Agulhas Current (AC) is $65 \mathrm{~Sv}$ and the IT strength is $10 \mathrm{~Sv}$. The deep inflow at the southern boundary is confined to below $3200 \mathrm{~m}$ and occurs mainly in the Perth Basin $\left(100^{\circ}-110^{\circ}\right.$ E; Fig. 5). These southern boundary conditions are applied in experiments A-D.

Experiment $\mathrm{E}$ uses $\theta$ and $\mathrm{S}$ from the Toole and Warren (1993) hydrographic section and $v$ from the flow field at $32^{\circ} \mathrm{S}$ estimated by G03 (the details of transformation onto the model grid are given in the appendix). The $\theta, S$, and $v$ fields contain a strong mesoscale signal and are much "spikier" than the FM boundary conditions (Fig. 6). Under these conditions the model bathymetry is modified to fit the hydrographic data and held constant over the latitudes $32^{\circ}-35^{\circ} \mathrm{S}$. This allows the model dynamics to smooth the flow before it encounters any changes in bathymetry. Previous model runs demonstrate that this improves the compatibility of the high-resolution hydrographic data with the rela-

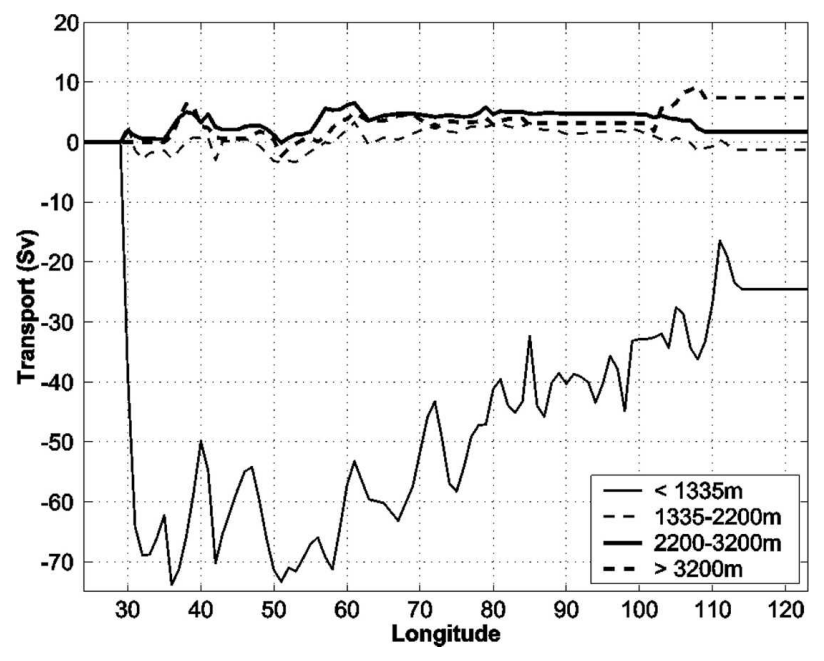

FIG. 6. As in Fig. 5, but for the G03 southern boundary conditions.

tively coarse-resolution ocean model. The size of the Agulhas Current is $70 \mathrm{~Sv}$ and the IT is $16 \mathrm{~Sv}$. In this case some of the deep inflow occurs above $3200 \mathrm{~m}$ at three zonal locations $\left(\sim 35^{\circ}-40^{\circ} \mathrm{E}, 55^{\circ}-65^{\circ} \mathrm{E}\right.$, and $100^{\circ}-$ $\left.110^{\circ} \mathrm{E}\right)$. The transformation of the $\mathrm{G} 03$ flow field at $32^{\circ} \mathrm{S}$ from isopycnal coordinates to the model grid (see the appendix) reduces the deep inflow to $9 \mathrm{~Sv}$, although it is still within the estimated uncertainty of $11 \pm 4 \mathrm{~Sv}$.

\section{Results}

In this section we describe the evolution of the overturning streamfunction at $28^{\circ} \mathrm{S}$ for all experiments (Fig. 7). For experiments A-D we monitor the streamfunction at 3200 and $1750 \mathrm{~m}$ for experiment $\mathrm{E}$. This is because the prescribed southern boundary flow field invokes a shallower overturning cell in experiment E. We go on to describe the changes in circulation and water mass properties for experiments $\mathrm{A}-\mathrm{D}$ and $\mathrm{E}$ in more detail in sections $6 \mathrm{a}$ and $6 \mathrm{~b}$, respectively.

In all model experiments there is a decrease in the overturning strength over the first few decades (Fig. 7). After 120 years of integration experiment $\mathrm{D}$ is near equilibrium, whereas experiments $\mathrm{A}-\mathrm{C}$ still show a small trend for decreasing the MOC at the end of the model run. Experiments A and C show similar evolution of the overturning streamfunction, presumably because the values of $K_{d}$ in experiment $\mathrm{C}$ over much of the water column are close to $2 \times 10^{-5} \mathrm{~m}^{2} \mathrm{~s}^{-1}$. Experiment B has the same basin-average $K_{d}$ as that of experiment $\mathrm{C}$ and demonstrates that the uniform $K_{d}$ is more efficient at sustaining the deep inflow. This is in agreement with Scott and Marotzke (2002), who found that diapycnal mixing is most effective at supporting the 


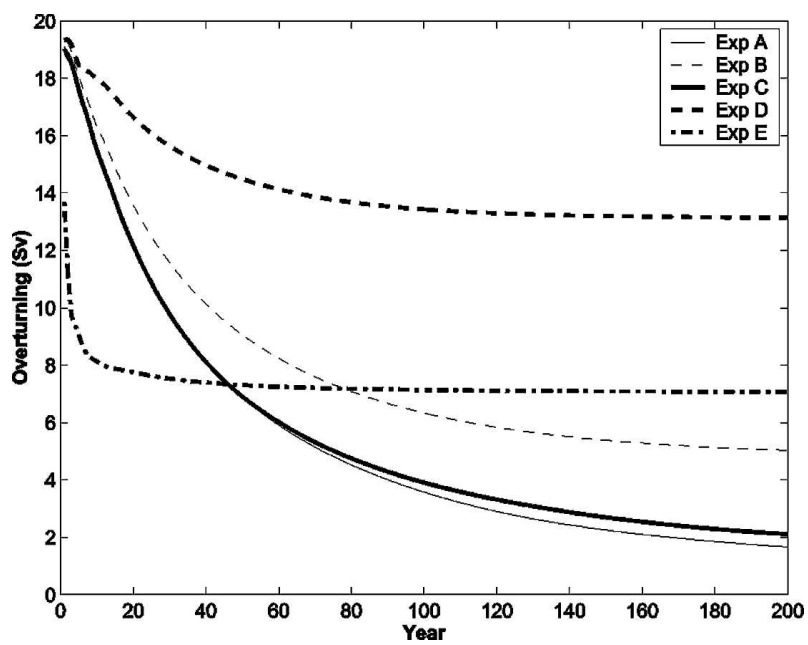

FIG. 7. Time-mean overturning streamfunction for year 1 of the FM solution. Flow is anticlockwise (clockwise) around positive (negative) features. The dashed line indicates the location of the Indonesian Throughflow.

MOC when it occurs in regions of strong stratification (mainly in the upper water column). Experiment D equilibrates much faster than experiments A-C and shows the largest overturning at year 200. Experiment E, which uses the G03 flow field at the southern boundary, equilibrates very rapidly and reaches quasi-steady state after only a few decades.

\section{a. Experiment $A-D$ results (Ferron and Marotzke configuration)}

The FM meridional overturning circulation, which is our reference circulation for experiments $\mathrm{A}-\mathrm{D}$, is characterized by an $18-\mathrm{Sv}$ cell at $3500 \mathrm{~m}$ that penetrates the basin to about $10^{\circ} \mathrm{N}$ (Fig. 8). As discussed in section $5 \mathrm{~b}$ the deep inflow prescribed at the southern boundary is mainly confined to the east, in the Perth Basin. This is the only location where model topography near $30^{\circ} \mathrm{S}$ permits a northward flow in the deepest model levels. In the first year of integration all experiments have a very similar overturning to the FM streamfunction (Fig. 8). It is only after a few years that the different $K_{d}$ regimes cause the model states to diverge. Using the model bathymetry we estimate a flushing time scale of $130 \mathrm{yr}$ for the abyssal Indian Ocean (>2200 m depth), based on an 18-Sv deep inflow.

Experiments $\mathrm{A}$ and $\mathrm{C}$ show similar temporal evolution of the streamfunction at $3200 \mathrm{~m}$ and $28^{\circ} \mathrm{S}$, but the different $K_{d}$ fields produce different zonally integrated circulations (Fig. 9). Experiment $\mathrm{C}$ has a clockwise overturning cell at about $1000 \mathrm{~m}$ that penetrates from the southern boundary to beyond $10^{\circ} \mathrm{N}$ and a slightly stronger deep circulation near $30^{\circ} \mathrm{S}$. By year 200 , ex-

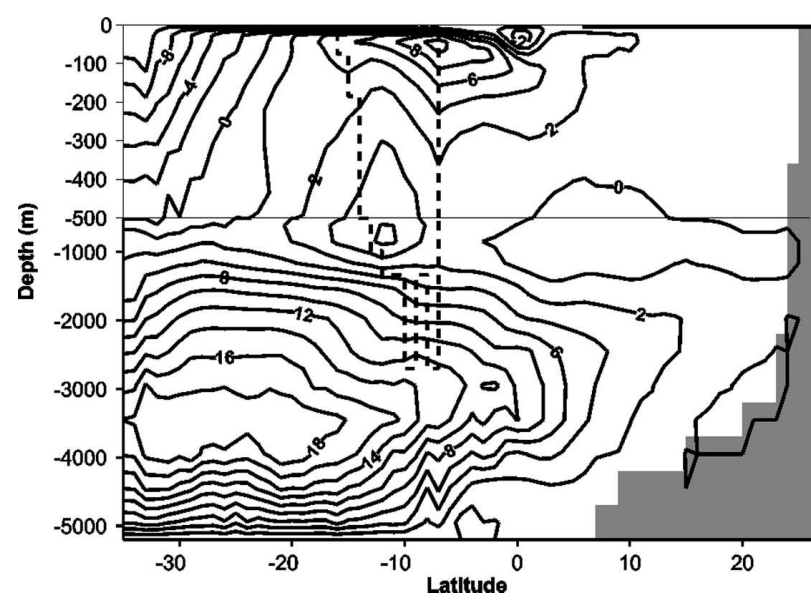

FIG. 8. Time series of the annual-mean overturning streamfunction (Sv) for $28^{\circ} \mathrm{S}$ at $3200 \mathrm{~m}$ for experiments A-D. The overturning streamfunction for experiment $\mathrm{E}$ is computed at $1750 \mathrm{~m}$, owing to the shallower overturning cell.

periments $\mathrm{A}$ and $\mathrm{C}$ show a similar near-surface circulation to year 1, but a near-complete collapse of the deep MOC. Experiment B shows a deeper near-surface circulation and a small residual deep overturning of 4 $\mathrm{Sv}$, which only penetrates to about $22^{\circ} \mathrm{S}$. Following the 4-Sv contour flow at $2000 \mathrm{~m}$ near the southern boundary descends to $4000 \mathrm{~m}$ as it moves northward and returns southward at about $1000 \mathrm{~m}$. At year 200 experiment $\mathrm{D}$ shows a similar near-surface circulation to experiment $\mathrm{B}$, but a much stronger deep overturning of 12 Sv. This deep overturning has weakened by $30 \%$ and is slightly deeper than at the start of the model run.

Using the overturning streamfunction we have established that for most $K_{d}$ regimes the overturning circulation in our Indian Ocean model diminishes relatively quickly as the model is integrated forward in time. To understand why the circulation changes it is necessary to look in more detail at the model state at the beginning and at the end of the model run. In the following sections we compare the end states of two model runs, experiment $\mathrm{C}$ (weak overturning) and experiment $\mathrm{D}$ (strong overturning), with the initial model state. Our analysis concentrates on the deep ocean and understanding why the deep MOC changes.

\section{1) Changes in the vertical $\theta$ Structure}

At the start of the model runs we observe a zonal gradient in potential temperature $(\theta)$ across Perth Ba$\sin \left(100^{\circ}-110^{\circ} \mathrm{E}\right.$, Fig. $\left.10 \mathrm{a}\right)$, which is associated with the large deep inflow (and associated vertical shear of meridional velocity) in this part of the basin. There are also deep zonal $\theta$ gradients visible at $40^{\circ} \mathrm{E}$ between the Mozambique Plateau and Madagascar Ridge and at 

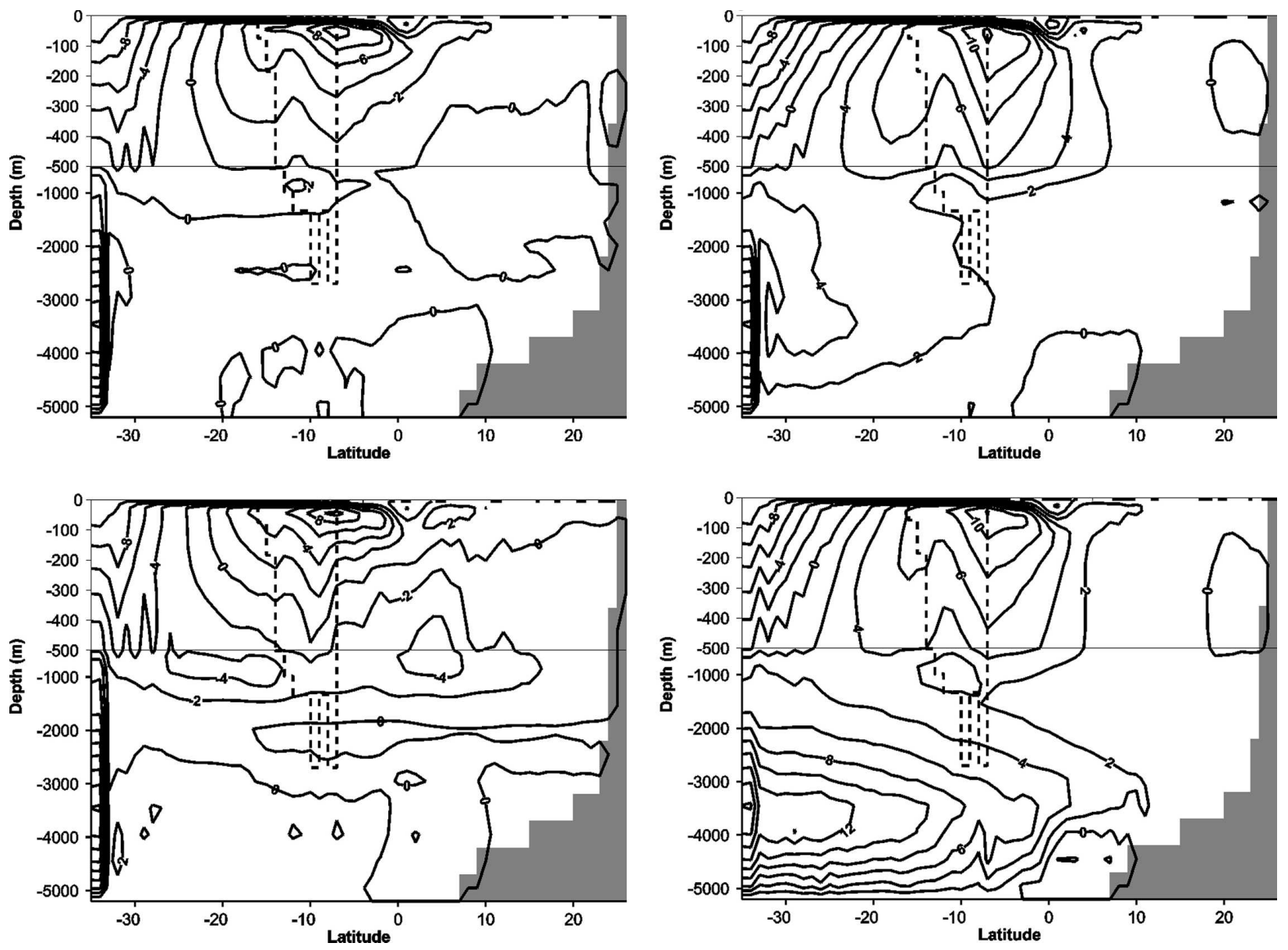

FIG. 9. Time mean overturning streamfunction (Sv) for year 200 of experiment (top left) A, (top right) B, (bottom left) C, and (bottom right) D. Flow is counterclockwise (clockwise) around positive (negative) features. The dashed line indicates the location of the Indonesian Throughflow.

$\sim 55^{\circ}-75^{\circ} \mathrm{E}$. The first of these gradients is located in a region of northward deep flow and the latter is a region of small southward flow (Fig. 6). The zonal average meridional $\theta$ section (Fig. 10b) shows a tongue of cold water from the Southern Ocean below about $3000 \mathrm{~m}$. The sloping of the isotherms implies a denser water column in the south and suggests a pressure gradient from south to north.

At the end of experiment $\mathrm{C}$ the zonal distribution of deep isotherms has changed substantially (Fig. 10c). The most striking changes are the removal of the $\theta$ gradient across Perth Basin at $40^{\circ} \mathrm{E}$. In both zonal and meridional sections there is evidence that the basin has been filled with cold, dense water originating from the south. The coldest water column is north of the southern boundary (Fig. 10d), suggesting a pressure gradient that would oppose the deep inflow into the basin.

After 200 years of model integration the mean $\theta$ of the ocean has dropped by $1.1^{\circ} \mathrm{C}$ and decreased in sa- linity by 0.01 . The largest temperature losses occur in the upper $1000 \mathrm{~m}$, with peak values at $33^{\circ} \mathrm{S}$ near the east and west boundaries. While there is a drop in the zonal mean surface temperature of a degree or so, the largest zonal mean drop in $\theta$ occurs over the depth range $20-200 \mathrm{~m}$. The change in surface temperature is constrained by relaxation to climatology, which is part of the surface boundary conditions. There are some isolated regions of temperature and salinity increase, which occur mainly between 500 and $2000 \mathrm{~m}$. The drift of $\theta / S$ properties in the model demonstrates that the flow regime in the ocean interior is not balanced with the surface forcings. There seems to be a problem in transferring heat, particularly, but also salt downward from the sea surface.

Experiment D shows less deviation from the initial conditions than experiment C. After 200 years of model integration the $\theta$ gradient across Perth Basin is preserved (Fig. 10e), though it is weaker than at the start of 

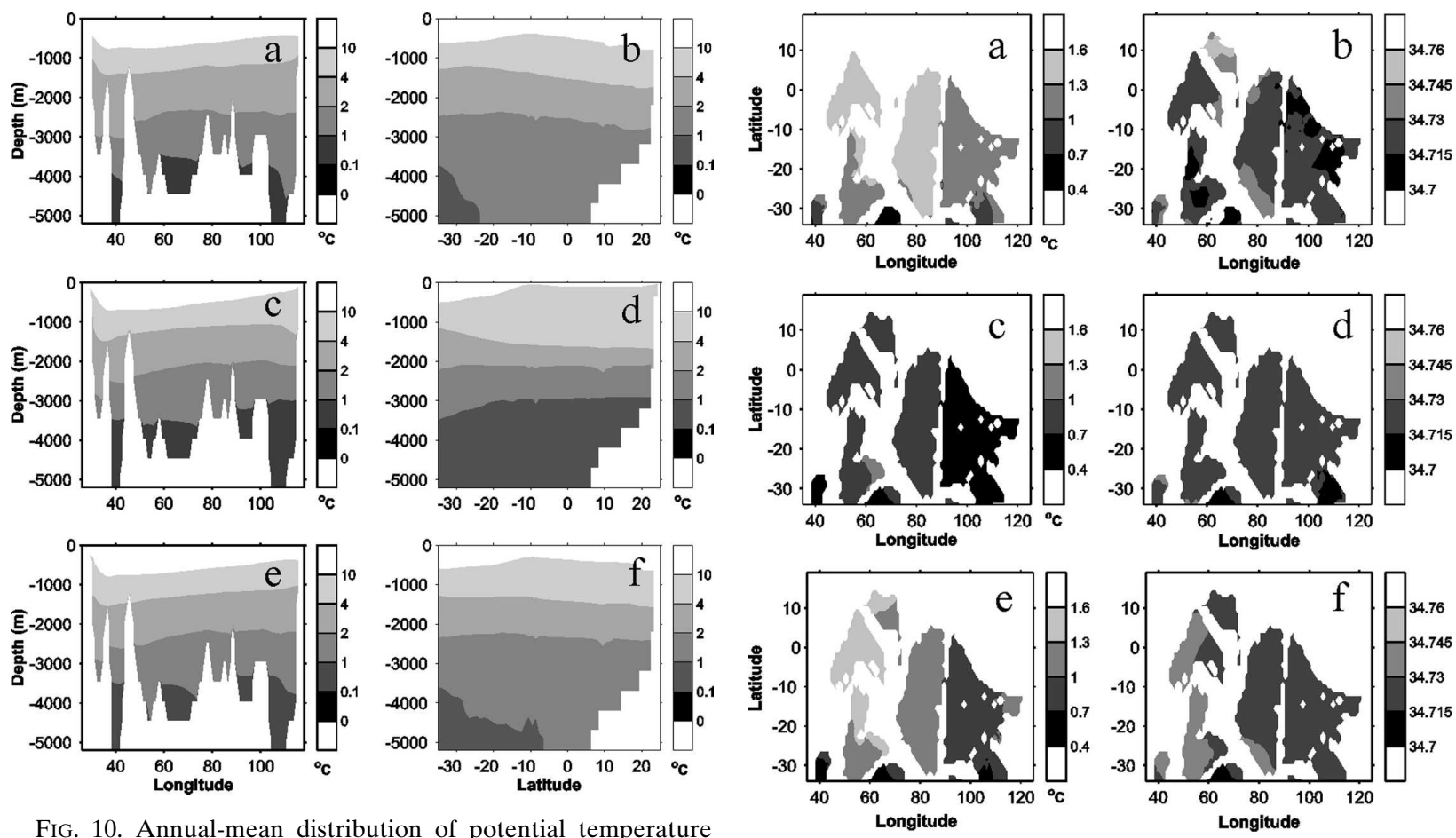

FIG. 10. Annual-mean distribution of potential temperature $\left({ }^{\circ} \mathrm{C}\right)$ for (left) a section at $33^{\circ} \mathrm{S}$ and (right) a meridional section of the zonal mean value. Data shown are (a), (b) year 1 of experiment C (representative of all model runs); (c), (d) year 200 of experiment C; and (e), (f) year 200 of experiment D.

the model run. The basic zonal structure of the deep isotherms is qualitatively similar to the start of the model run. There is evidence of filling of the Indian Ocean subbasins, but to a lesser extent than previous model runs (Figs. 10e,f).

The basin-mean $\theta$ has fallen by $0.58^{\circ} \mathrm{C}$ and salinity has dropped by 0.027 . While the drift in $\theta$ is halved compared to experiment $\mathrm{C}$, the drift in $\mathrm{S}$ has more than doubled. This is, no doubt, a consequence of more of the relatively fresh deep water from the southern boundary being advected and mixed in the model interior. Again the largest changes occur in the upper $1000 \mathrm{~m}$.

\section{2) Changes in the Deep-water $\theta$ And $S$}

At the start of the model runs the deep subbasins of the ocean model show a definite horizontal structure in $\theta$ and $S$ (Figs. 11a,b). The cold influence of the southern boundary and the high $S$ in the northernmost basin are particularly striking. Again we observe a strong zonal temperature gradient in Perth Basin $\left(105^{\circ}-110^{\circ} \mathrm{E}\right)$. It is apparent that the Madagascar $\left(50^{\circ}-60^{\circ} \mathrm{E}\right)$ and Perth Basins provide the only entrances to the interior deep ocean basins at the southern boundary. The distribution of salinity gives the impression that the central Indian basin is filled from the West Australian Basin

FIg. 11. (left) Potential temperature and (right) salinity averaged over the deepest three model levels $(>3700 \mathrm{~m})$. Data shown are (a), (b) year 1 of experiment $\mathrm{C}$ (representative of all model runs); (c), (d) year 200 of experiment C; and (e), (f) year 200 of experiment D.

via a gap in the Ninetyeast Ridge, as suggested by observations (Warren and Johnson 2002).

After 200 years of integration of experiment $C$ the water in the deep subbasins has been homogenized: there is no longer evidence of any large property gradients and the mean $\theta$ has dropped substantially (Figs. $11 \mathrm{c}, \mathrm{d})$. At the end of experiment $\mathrm{D}$ the deep subbasins show some homogenization of water mass properties, but there is some preservation of the original horizontal gradients of $\theta$ and $S$ (Figs. 11e,f).

\section{3) Changes in the abyssal circulation}

The FM abyssal circulation (below 3200 m, Fig. 12a) compares favorably with Reid (2003). There is northward flow along the western flanks of the Madagascar, Central Indian, Perth, and West Australian Basins. However, the model shows a southward flow in the Somali Basin, where Reid suggests a continuation of the northward flow from the Madagascar Basin. At year 200, experiments A-C show a change to southward flow in the Madagascar Basin and a reduction in magnitude of the abyssal circulation consistent with the drop in the deep overturning strength. At year 200 experiment $\mathrm{D}$ retains the northward flow along the west- 

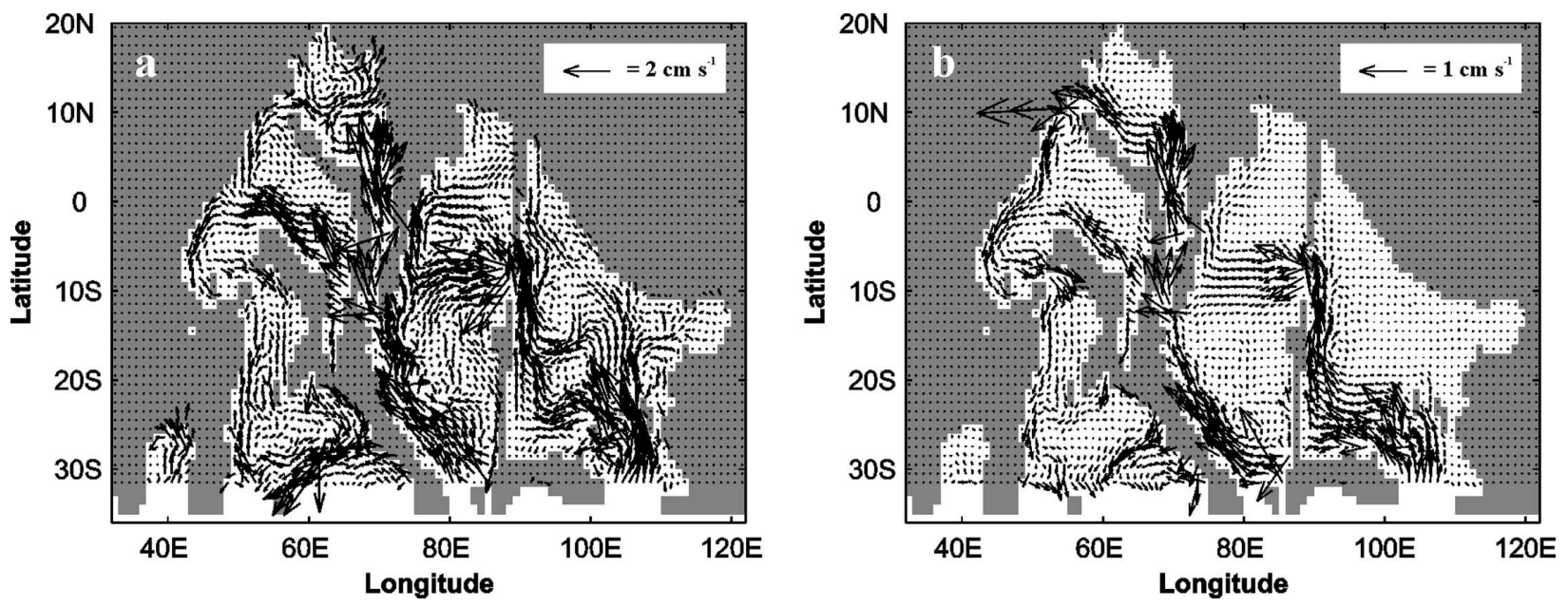

FIG. 12. Velocity vectors of the time mean circulation below $3200 \mathrm{~m}$ for the (a) FM solution and (b) year 200 of experiment D. Bathymetry shallower than $3200 \mathrm{~m}$ is shaded.

ern flank of the Madagascar Basin and looks similar to the FM abyssal circulation (Fig. 12b). However, there are some qualitative changes in the circulation of some of the subbasins, particularly north of the equator.

\section{b. Experiment E results (Ganachaud configuration)}

After a steep decline in the overturning strength over the first decade, experiment $\mathrm{E}$ rapidly equilibrates (Fig. 7). The implication is that the southern boundary velocity field and the model diapycnal mixing are closer to a dynamic equilibrium at the start of experiment $E$ than the previous model experiments. The initial decrease in overturning from a larger value than prescribed at the southern boundary suggests that the FM initial conditions may contribute to a strong, but transient, initial overturning. After 200 years of model integration the peak deep overturning in the model interior is $8 \mathrm{~Sv}$, which represents $90 \%$ of the $9 \mathrm{~Sv}$ prescribed deep inflow. The overturning cell is substantially weaker and shallower than the FM solution and penetrates the basin no farther than the equator (Fig. 13). As with the previous model runs, experiment $\mathrm{E}$ shows a drift in basin-integrated temperature and salinity. The drop in $\theta$ is $0.7^{\circ} \mathrm{C}$ and the mean $S$ is reduced by 0.05 . The loss of heat and salt occurs predominantly in the nearsurface layers. As with previous experiments, the greatest drop in zonal-mean $\theta$ occurs in the 20-200-m depth range.

At year 200 the abyssal circulation of experiment $\mathrm{E}$ shows northward flow along the flanks of the Madagascar, Somali, Perth, and West Australian Basins (Fig. 14), which is in qualitative agreement with Reid (2003). However, the model exhibits a southward flow on the western flank of the central Indian basin, which is at odds with the estimates of Reid. The southward model flow in this region is consistent with a small southward transport in the deepest model levels near $85^{\circ} \mathrm{E}$ associated with the G03 southern boundary velocity field (Fig. 6).

\section{Discussion}

Experiments A-D demonstrate that the distribution of diapycnal diffusivity $K_{d}$ has a profound impact on the size of the quasi-steady overturning state. Using the FM uniform $K_{d}$ of $2 \times 10^{-5} \mathrm{~m}^{2} \mathrm{~s}^{-1}$ we see a near-

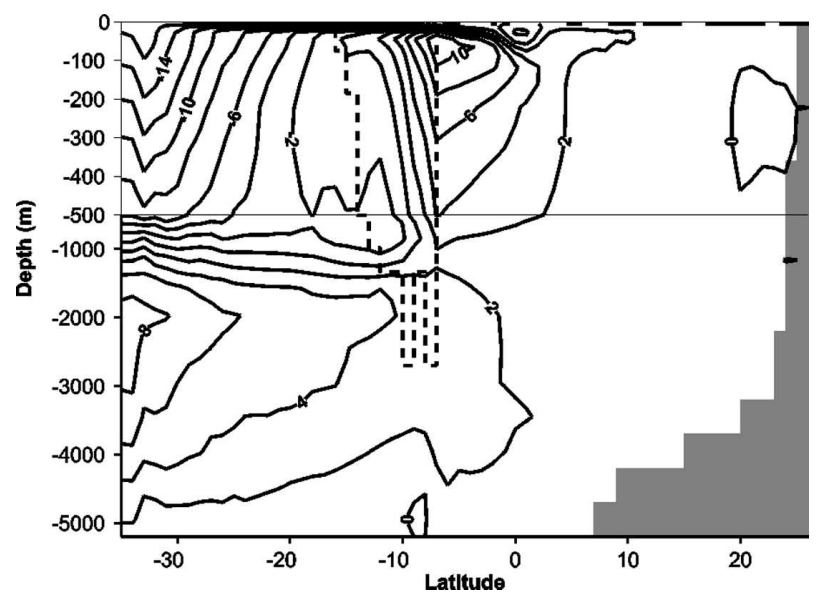

FIG. 13. Time-mean overturning streamfunction (Sv) for year 200 of the Ganachaud solution. Flow is anticlockwise (clockwise) around positive (negative) features. The dashed line indicates the location of the Indonesian Throughflow. 


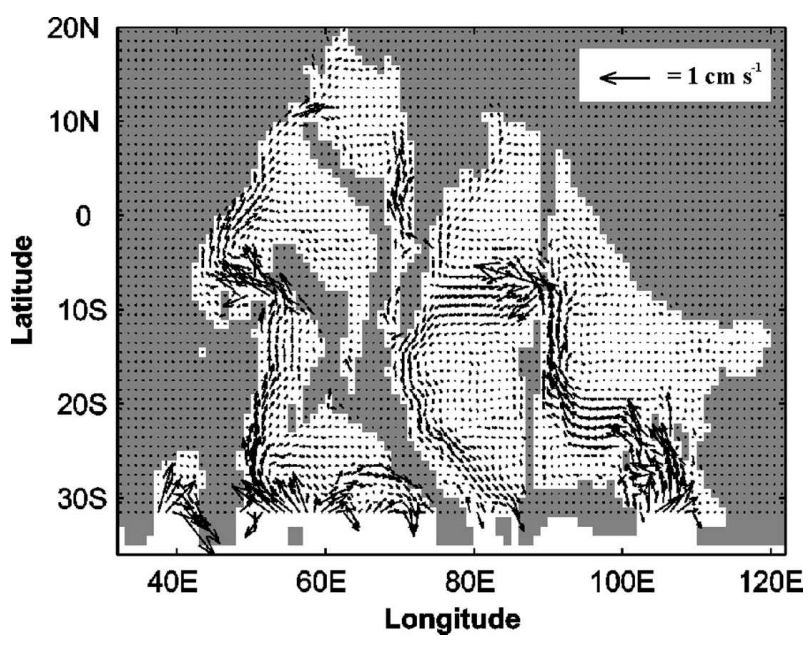

FIG. 14. Velocity vectors of the time-mean circulation below $3200 \mathrm{~m}$ for year 200 of experiment E; bathymetry shallower than $3200 \mathrm{~m}$ is shaded.

complete collapse of the 18 -Sv overturning cell after 200 years of model integration. A similar result is obtained when one implements the observationally based $K_{d}$ estimates. Presumably this is because the "observed" $K_{d}$ over much of the water column is close to $2 \times 10^{-5} \mathrm{~m}^{2} \mathrm{~s}^{-1}$, despite very large values at depth. This point is elucidated by Scott and Marotzke (2002), who found that diapycnal mixing was most efficient at sustaining a large MOC when it occurred in regions of strong stratification, that is, the low-latitude thermocline. The Scott and Marotzke finding is supported by experiment $\mathrm{B}$, which has larger $K_{d}$ values in the upper water column than experiment $\mathrm{C}$, but the same basin-integrated value. Experiment $\mathrm{D}$ uses diagnosed $K_{d}$ from a 1D advection-diffusion balance and the FM circulation, and shows a quasi-steady overturning circulation of $12 \mathrm{~Sv}$. This accounts for $70 \%$ of the $18-\mathrm{Sv}$ overturning prescribed at the southern boundary. Diagnosed $K_{d}$ is also effective in sustaining a quasi-steady overturning state as inferred from observations (experiment $\mathrm{E})$. In this case $90 \%(8 \mathrm{~Sv})$ of the 9 -Sv prescribed overturning is preserved after 200 years of integration. However, the model shows a much-reduced meridional extent to the overturning, compared to the original box model estimate (G03). The 1D advection-diffusion balance used here is likely to be even more effective in an isopycnal model, where $K_{d}$ would be associated with the interface between isopycnals and therefore track with movement of isopycnals. The diagnosed $K_{d}$ presented here could be improved by a priori mapping the isopycnal surfaces in the model interior and producing several $K_{d}$ profiles as a function of latitude.

The fact that experiment $E$ exhibits an interior quasi- steady overturning that represents $90 \%$ of the overturning associated with the prescribed southern boundary velocity field, whereas experiment $\mathrm{D}$ achieves only $70 \%$, could be related to the zonal structure of the deep inflow. In both cases applying a 1D advective-diffusive balance means that the $K_{d}$ field is zonally uniform, but the prescribed deep inflows have varying degrees of zonal asymmetry. The vast majority of the FM (experiment D) northward transport below $2200 \mathrm{~m}$ occurs east of $90^{\circ} \mathrm{E}$ (Fig. 6). In this case the deep inflow is cut off from much of the diapycnal mixing potential associated with the $K_{d}$ field in the west of the basin by a series of meridional ridges. In contrast, the G03 flow field (experiment E) has a number of locations of northward transport below $2200 \mathrm{~m}$ (Fig. 8), which is better able to utilize the mixing potential of the zonally uniform $K_{d}$ field. If this plausible theory is correct, it means that to reproduce a realistic MOC in the Indian Ocean onr requires a good correspondence between the zonal structure of the deep inflow and locations of diapycnal mixing. In other words, knowing the zonal-mean $K_{d}$ profile (e.g., diagnosed from a 1D advection-diffusion balance) is not enough. Despite this, the $1 \mathrm{D}$ advectiondiffusion balance provides a good first estimate of the distribution of the $K_{d}$ required to support a specified deep inflow.

\section{a. Why does the overturning circulation collapse?}

The thermal wind equation states that a meridional MOC requires a zonal density gradient to support the vertical shear of northward velocity. At the southern boundary the deep inflow is prescribed, so the model has no "choice" until it enters the ocean interior. Experiments $\mathrm{A}$ and $\mathrm{C}$ show large homogenization of the deep-water masses and a removal of the temperature gradient across Perth Basin after 200 years of integration. At the end of these model runs the deep inflow is not sustained upon entering the model domain, and there is a dramatic reduction in the zonal density gradient. The prescribed flow cannot move northward, but mass conservation dictates that the flow must go somewhere. It is possible that the flow could move zonally, if there were a substantial meridional density gradient, but only until it encountered topography. In practice, the easiest solution seems to be for the flow to move upward. Analysis of the $u$ - and $w$-velocity components (not shown) shows that most of the deep inflow is directed upward upon entering the model domain and then flows zonally across the basin to the Agulhas Current, where it is advected out of the model domain. Such a flow pattern requires a pressure gradient to oppose the deep northward flow prescribed at the southern boundary, which could be supplied by the largely 
homogenous water mass in Perth Basin (Figs. 10c and $11 \mathrm{c}, \mathrm{d})$. The circulation regimes that show some residual deep overturning all manage to preserve zonal gradients in the ocean interior, to a greater or lesser extent.

In the ocean interior the amount of diapycnal mixing $\left(d_{\text {mix }}\right)$ that occurs at any location is a function of the diapycnal diffusivity $\left(K_{d}\right)$ and the local diapycnal density gradient (approximately $\partial \rho / \partial z$ ), such that $d_{\text {mix }}=$ $K_{d} \partial \rho / \partial z$. If the basinwide $d_{\text {mix }}$ is not large enough to balance the mass of deep water flowing into the ocean basin, the stratification above the deep inflow (and $\partial \rho /$ $\partial z$ ) will increase (e.g., Fig. 10d, 1500-3000 m). Eventually $\partial \rho / \partial z$ (and therefore $d_{\text {mix }}$ ) becomes large enough to balance the deep inflow. Hence all model experiments reach some form of quasi-steady state. Any changes in the areas of the isopycnals can also contribute to the basinwide $d_{\text {mix }}$, but this so-called hypsographic effect was found to be negligible when determining the basinwide values for $K_{d}$ from the LADCP data. It is therefore unlikely to play a major role here.

\section{b. Heat loss in the upper water column}

The loss of heat in the ocean basin and particularly in the upper $1000 \mathrm{~m}$ is a feature of all model runs. The heat loss arises because the deep ocean basin is filled with the cold water originating from the southern boundary. Model runs with the weakest $K_{d}$ values and correspondingly weak MOC show the greatest heat loss since a greater volume of the basin becomes filled with cold water. In the deep ocean the change in mean temperature, and hence the heat loss, is relatively small. However, the upper water column exhibits a large heat loss since here the cold deep water upwells into much warmer water, leading to a substantial drop in temperature. The surface forcing includes a restorating term, so the uppermost model levels are unable to change much from the initial conditions. Hence the greatest heat loss occurs in the intermediate levels of the upper water column. The implication for all model runs is that the $K_{d}$ values in the upper water column are not large enough to transfer sufficient heat downward to compensate for the upwelling of deep water. It is possible that changes in subduction also influence the stratification of the upper ocean. However, since all model runs use the same surface forcings, it is unlikely that changes in subduction play a major role.

The fact that all model runs show heat loss (and loss of salt to a lesser extent) suggests that there is a fundamental problem in transferring heat downward in the GCM. FM noted that, when their solution was integrated forward for a few years, the heat content in the upper $500 \mathrm{~m}$ rapidly decreased. They suggested that this could be due to inadequate mixed layer physics and/or inaccurate estimates of the surface heat and freshwater fluxes. The authors also noted a decline in the overturning to about $12 \mathrm{~Sv}$ after the first 10 years and suggest that the uniform $K_{d}$, the possibility of misrepresented bathymetry, and poor model resolution might make it impossible to sustain the deep circulation. We have demonstrated that given appropriate $K_{d}$ a large part of the overturning circulation can be sustained indefinitely. However, we also observe a cooling of the upper water column, despite the large nearsurface $K_{d}$ values used in some model runs. A possible implication is that the FM surface fluxes are too weak.

\section{Summary and conclusions}

After $200 \mathrm{yr}$, the 18-Sv deep overturning cell present in year 1 of the FM model configuration has collapsed, leaving a residual circulation of $<2 \mathrm{~Sv}$. Both with uniform diapycnal diffusivity $\left(K_{d}\right)$ close to the canonical value of $10^{-4} \mathrm{~m}^{2} \mathrm{~s}^{-1}$ (Munk 1966; Munk and Wunsch 1998 ) and a $2 \mathrm{D}$ field, $K_{d}($ lat, $z$ ), estimated from hydrographic data (following Naveira Garabato et al. 2005), the overturning circulation again collapses, with the uniform $K_{d}$ supporting the larger residual circulation ( $\sim 4 \mathrm{~Sv})$. The decline in the deep overturning is consistent with the removal of zonal density gradients at depth and homogenization of the deep ocean. Both of these effects are the result of an imbalance between the diapycnal mixing and the large deep inflow.

When the $K_{d}$ field necessary to sustain the FM overturning indefinitely is diagnosed, by considering the mass balance into isopycnal layers at the southern boundary we are able to preserve $70 \%$ of the FM overturning strength in a quasi-steady state. The diagnosed $K_{d}$ values are much larger than our observationally based estimates. The FM solution is characterized by a large deep inflow ( $>10 \mathrm{~Sv}$ ) in Perth Basin that is not supported by recent current meter mooring estimates of 4.4-5.8 Sv below $3200 \mathrm{~m}$ (Sloyan 2006). In addition, the FM values of $K_{d}$ can be shown to require more than half of the $\sim 2$ TW (terawatts) available to drive the global overturning (Munk and Wunsch 1998; Wunsch and Ferrari 2004). We thus conclude that the FM solution is unlikely to be a realistic quasi-steady overturning state for the Indian Ocean.

With $K_{d}$ diagnosed from the G03 estimate of the flow field at $32^{\circ} \mathrm{S}, 90 \%$ of the 9 -Sv overturning applied at the southern boundary is sustained in quasi-steady state. The results suggest that there must be good correspondence between the locations of deep inflow and the diapycnal mixing field to maximize the quasi-steady state MOC. The net flow below $3200 \mathrm{~m}$ in Perth Basin shows agreement with the recent current meter moor- 
ing estimates of Sloyan (2006). The values of $K_{d}$ required for the Ganachaud flow field are much less than those required for FM and fall within the range of observational estimates below $3000 \mathrm{~m}$. However, for the upper water column they are still an order of magnitude larger than the observational estimates. The Ganachaud flow field also invokes a southward flow on the western flank of central Indian basin, which is inconsistent with the circulation estimates of Reid (2003).

At least in the experiments presented here, the observational estimates of $K_{d}$ are not able to support a steady-state deep MOC in the Indian Ocean of more than a few Sverdrups. However, the observational sampling is extremely sparse and we may be missing some important dynamics in our use of zonally averaged values of $K_{d}$. A logical next step would be to make $K_{d}$ a control parameter in an adjoint assimilation scheme, using a similar method to that of FM. This approach could be used to find the $K_{d}$ distribution that best preserves the model state at the start of the model forward integration. Limited computing resources mean that this method is beyond the scope of the current investigation.

The work presented here suggests that the Indian Ocean deep MOC reaches a quasi-steady state on century time scales and is determined by the distribution of $K_{d}$. The distribution of $K_{d}$ required to support the prescribed deep inflow at the southern boundary implies highly nonuniform profiles of $K_{d}$ in quasi-steady state for two different estimates of the flow field near $32^{\circ} \mathrm{S}$. Observation-based estimates of $K_{d}$ also suggest a highly nonuniform distribution of $K_{d}$. It is therefore essential to improve our understanding of the oceanic $K_{d}$ distribution and implement a nonuniform $K_{d}$ distribution in ocean and coupled ocean-atmosphere models that are run to quasi-equilibrium states. In reality, $K_{d}$ and $\partial \rho / \partial z$ are linked and $K_{d}$ should therefore evolve with the ocean dynamics. This can be achieved for ocean GCMs by implementing mixing parameterizations based on energetic arguments (Huang 1999) as demonstrated by Simmons et al. (2004).

Acknowledgments. We thank Bruno Ferron for providing the FM Indian Ocean model configuration, Elaine McDonagh for providing the 1987 hydrographic data, and Alex Ganachaud for providing his estimate of the 1987 flow field at $32^{\circ} \mathrm{S}$. We are grateful to Harry Bryden, Teri Chereskin, and Eric Firing for providing the LADCP data from the CD139, WOCE I01, and WOCE I02 research cruises. We also thank two anonymous reviewers whose comments helped to improve this paper. This work was completed as part of MDP's Ph.D. work at the National Oceanography Centre,
Southampton, United Kingdom funded by NERC Grant NER/A/S/2000/00438. A NERC postdoctoral research fellowship (NER/I/S/2001/00727) supported A. C. Naveira Garabato during this work.

\section{APPENDIX}

\section{Grid Transformation and Box Averaging}

Here we describe how meridional velocity $(v)$, potential temperature $(\theta)$, and salinity $(S)$ from $\mathrm{G} 03$ are transformed onto the model grid. Ganachaud's estimate of the velocity field at $32^{\circ} \mathrm{S}$ was partitioned into 11 isoneutral layers for the 106 hydrographic stations occupied in 1987 (Toole and Warren 1993).

\section{a. Transformation of $v, \theta$, and $S$ onto the model grid}

Absolute transport fields in isoneutral layers from G03 are transformed onto the model vertical grid using a "box-averaging" method (see below). The bathymetry at the southern boundary is determined by the Ganachaud meridional transport field: wherever any transport occurs in the location of a model grid cell, that grid cell is set to an ocean cell. Any grid cells with no transport attributed to them at the end of the transformation are set to land cells. In this way we are best able to preserve the integrated transports of Ganachaud (2003). Any transport that occurs below the model seafloor $(5200 \mathrm{~m})$ is added to the deepest model grid cell (4700-5200 m).

The first step in the transformation of $\theta$ and $S$ onto the model grid is to remove the land points in the hydrographic data. This is achieved by linearly interpolating across topographic features, such as ocean ridges, and extrapolating the deepest values downward (Fig. A1). Although this process results in some artificial mixing of water masses separated by topographic ridges, the effect is minimal since these regions are later masked by topography. The horizontal linear interpolation and downward extrapolation of water properties prevents contamination of the data with missing values in the later stages of the transformation. The next step is to transform the data onto the model vertical grid. For the upper seven model vertical levels $(0-135 \mathrm{~m})$, the vertical resolution of the model grid is similar to the 20-db grid of the observations. For these vertical levels a simple linear interpolation scheme is used to determine the values on the model grid. For the deeper model levels a more sophisticated "box-averaging" algorithm is used, which is designed to preserve the section-integrated properties. Once the hydrographic 

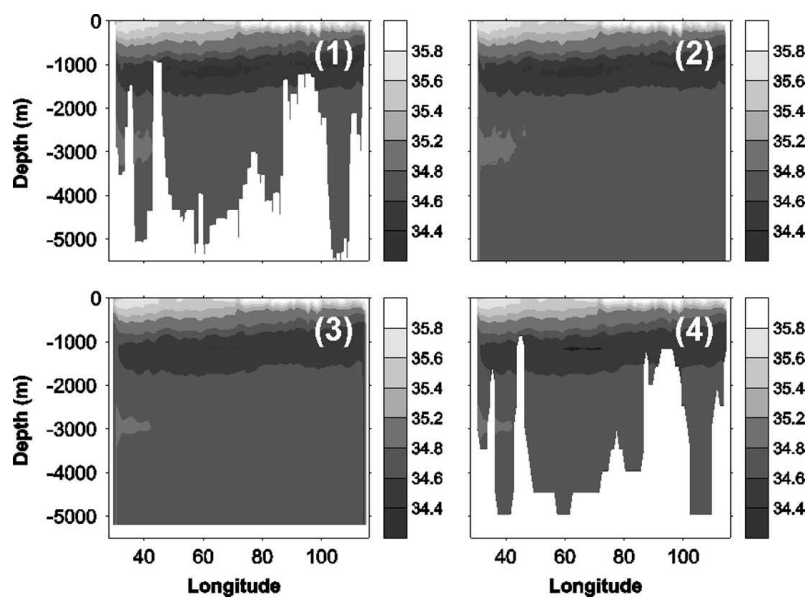

FIG. A1. Contour plots of $S$ for the 1987 section to illustrate the transformation of hydrographic $\theta$ and $S$ onto the model grid. 1) The original hydrographic section $(106 \times 303$ matrix $) ; 2)$ interpolated across bathymetry and filled downward $(106 \times 303$ matrix $)$; $3)$ area-mean transformed data onto model grid $(100 \times 22$ matrix); 4) masked data on model grid $(100 \times 22$ matrix $)$.

data have been transformed onto the model vertical grid they are transformed onto the model horizontal grid, again using the box-averaging method. The exceptions are the grid cells adjacent to the eastern and western boundaries. At these locations, water properties are determined by "hand picked" hydrographic stations of sufficient depth to reach the model seafloor. This avoids contamination of the data near the boundaries (the boundaries can be thought of as topography that cannot be interpolated across). In the final step the $\theta$ and $S$ fields are masked with the model bathymetry. The transformation process is shown pictorially in Fig. A1.

\section{b. Box averaging}

Here we describe the box-averaging method used in the transformation of data from the hydrographic grids to the model grid. Referring to the schematic (Fig. A2), $\phi$ is the water mass property to be transformed onto the model grid $(\theta$ or $S$ ) and $A$ is the area on the hydrographic grid associated by each value of $\phi$. When we overlay the model grid, a number of hydrographic grid cells is either completely or partly contained within the borders of each model grid cell. If $a_{n}$ is the area of each subbox contained within each model cell, the value of $\phi$ attributed to the model grid box is calculated as

$$
\phi_{\text {model }}=\frac{\sum_{n=1: 4} \phi_{n} a_{n}}{\sum_{n=1: 4} a_{n}} .
$$
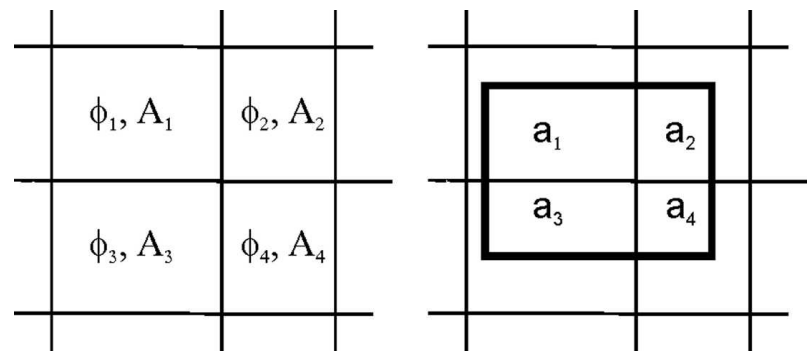

FIG. A2. (left) Schematic of the hydrographic grid and (right) again with a single model grid cell overlaid on top: $\phi_{1}-\phi_{4}$ represent water mass properties, $A_{1}-A_{4}$ are areas of the hydrographic grid cells, and $a_{1}-a_{4}$ represent subareas within the model grid cell.

The calculation is performed in a two-stage process, making first a 1D "line average" in the vertical, followed by the same routine oriented in the horizontal. The net effect is exactly that described in Fig. A2. The advantage with the box-average approach over lesssophisticated interpolation routines is that it conserves the section-integrated quantities.

\section{REFERENCES}

Armi, L., 1978: Some evidence for boundary mixing in the deep ocean. J. Geophys. Res., 83, 1971-1979.

Bryden, H. L., 2003: RRS Charles Darwin Cruise 139, 01 Mar-15 April 2002, Trans-Indian hydrographic section across 32S. Southampton Oceanography Centre Cruise Rep. 45, 122 pp. _ , and L. M. Beal, 2001: Role of the Agulhas Current in Indian Ocean circulation and associated heat and freshwater fluxes. Deep-Sea Res. I, 48, 1821-1845.

—, and A. J. G. Nurser, 2003: Effects of strait mixing on ocean stratification. J. Phys. Oceanogr., 33, 1870-1872.

Danabasoglu, G., J. C. McWilliams, and P. R. Gent, 1994: The role of mesoscale tracer transports in the global ocean circulation. Science, 264, 1123-1126.

Ferron, B., and J. Marotzke, 2003: Impact of 4D-variational assimilation of WOCE hydrography on the meridional circulation of the Indian Ocean. Deep-Sea Res. II, 50, 2005-2021.

Ganachaud, A., 2003: Large-scale mass transports, water mass formation, and diffusivities estimated from World Ocean Circulation Experiment (WOCE) hydrographic data. J. Geophys. Res., 108, 3213, doi:10.1029/2002JC001565.

_ C. C. Wunsch, J. Marotzke, and J. Toole, 2000: Meridional overturning and large-scale circulation of the Indian Ocean. J. Geophys. Res., 105, $26117-26134$.

Garternicht, U., and F. Schott, 1997: Heat fluxes of the Indian Ocean from a global eddy-resolving model. J. Geophys. Res., 102, 21 147-21 159.

Gent, P. R., and J. C. McWilliams, 1990: Isopycnal mixing in ocean circulation models. J. Phys. Oceanogr., 20, 150-155.

Gouretski, V. V., and K. P. Koltermann, 2004: WOCE global hydrographic climatology. Berichte des Bundesamtes für Seeschifffahrt und Hydrographie Tech. Rep. 35/2004, 55 pp.

Griffies, S. M., A. Gnanadesikan, R. C. Pacanowski, V. D. Larichev, J. K. Dukowicz, and R. D. Smith, 1998: Isoneutral diffusion in a $z$-coordinate ocean model. J. Phys. Oceanogr., 28, 805-830. 
Hasumi, H., and N. Suginohara, 1999: Effects of locally enhanced vertical diffusivity over rough bathymetry on the world ocean circulation. J. Geophys. Res., 104, 23 367-23 374.

Huang, R. X., 1999: Mixing and energetics of the oceanic thermohaline circulation. J. Phys. Oceanogr., 29, 727-746.

Johnson, G. C., D. L. Musgrave, B. A. Warren, A. Ffield, and D. B. Olson, 1998: Flow of bottom and deep water in the Amirante Passage and Mascarene Basin. J. Geophys. Res., 103, 30 973-30 984.

Kalnay, E., and Coauthors, 1996: The NCEP/NCAR 40-Year Reanalysis Project. Bull. Amer. Meteor. Soc., 77, 437-471.

Kunze, E., E. Firing, J. M. Hummon, T. K. Chereskin, and A. Thurnherr, 2006: Global abyssal mixing inferred from lowered ADCP shear and CTD strain profiles. J. Phys. Oceanogr., 36, 1553-1576.

Ledwell, J. R., E. T. Montgomery, K. L. Polzin, L. C. St. Laurent, R. W. Schmitt, and J. M. Toole, 2000: Evidence for enhanced mixing over rough topography in the abyssal ocean. Nature, 403, 179-182.

Lee, T., and J. Marotzke, 1997: Inferring meridional mass and heat transports of the Indian Ocean by fitting a general circulation model to climatological data. J. Geophys. Res., 102, $10585-10602$.

—, and — 1998: Seasonal cycles of meridional overturning and heat transport of the Indian Ocean. J. Phys. Oceanogr., 28, 923-943.

Levitus, S., and T. P. Boyer, 1994: Temperature. Vol. 4, World Ocean Atlas 1994, NOAA Atlas NESDIS 4, 117 pp.

—, R. Burgett, and T. P. Boyer, 1994: Salinity. Vol. 3, World Ocean Atlas 1994, NOAA Atlas NESDIS 3, 99 pp.

Mantyla, A. W., and J. L. Reid, 1995: On the origins of deep and bottom waters of the Indian Ocean. J. Geophys. Res., 100, 2417-2439.

Marshall, J., A. Adcroft, C. Hill, L. Perelman, and C. Heisey, 1997a: A finite-volume, incompressible Navier Stokes model for studies of the ocean on parallel computers. J. Geophys. Res., 102, 5753-5766.

—, C. Hill, L. Perelman, and A. Adcroft, 1997b: Hydrostatic, quasi-hydrostatic, and nonhydrostatic ocean modeling. $J$. Geophys. Res., 102, 5733-5752.

Munk, W., 1966: Abyssal recipes. Deep-Sea Res., 13, 707-730.

_ , and C. Wunsch, 1998: Abyssal recipes II: Energetics of tidal and wind mixing. Deep-Sea Res. I, 45, 1977-2010.

Naveira Garabato, A. C., K. L. Polzin, B. A. King, K. J. Heywood, and M. Visbeck, 2004: Widespread intense turbulent mixing in the Southern Ocean. Science, 303, 210-213.

- , H. L. Bryden, and E. L. McDonagh, 2005: Closing the overturning circulation of the Indian Ocean: The mixing perspective. Geophys. Res. Abstr., 7, Abstract EGU05-A-05052.

Polzin, K. L., J. M. Toole, J. R. Ledwell, and R. W. Schmitt, 1997:
Spatial variability of turbulent mixing in the abyssal ocean. Science, 276, 93-96.

Redi, M. H., 1982: Oceanic isopycnal mixing by coordinate rotation. J. Phys. Oceanogr., 12, 1154-1158.

Reid, J. L., 2003: On the total geostrophic circulation of the Indian Ocean: Flow patterns, tracers, and transports. Prog. Oceanogr., 56, 137-186.

Robbins, P. E., and J. M. Toole, 1997: The dissolved silica budget as a constraint on the meridional overturning circulation of the Indian Ocean. Deep-Sea Res. I, 44, 879-906.

Scott, J. R., and J. Marotzke, 2002: The location of diapycnal mixing and the meridional overturning circulation. J. Phys. Oceanogr., 32, 3578-3595.

Shi, W., J. M. Morrison, and H. L. Bryden, 2002: Water, heat and freshwater flux out of the northern Indian Ocean in September-October 1995. Deep-Sea Res. II, 49, 1231-1252.

Simmons, H. L., S. R. Jayne, L. C. St. Laurent, and A. J. Weaver, 2004: Tidally driven mixing in a numerical model of the ocean general circulation. Ocean Modell., 6, 245-263.

Sloyan, B. M., 2006: Antarctic bottom and lower circumpolar deep water circulation in the eastern Indian Ocean. J. Geophys. Res., 111, C02006, doi:10.1029/2005JC003011.

— , and S. R. Rintoul, 2001: The Southern Ocean limb of the global deep overturning circulation. J. Phys. Oceanogr., 31, 143-173.

Stammer, D., C. Wunsch, R. Giering, Q. Zhang, J. Marotzke, J. Marshall, and C. N. Hill, 1997: The global ocean circulation estimated from TOPEX/Poseidon altimetry and the MIT general circulation model. MIT Center for Global Change Science Rep. 49, Massachusetts Institute of Technology, Cambridge, MA, 40 pp.

, and Coauthors, 2003: Volume, heat, and freshwater transports of the global ocean circulation 1993-2000, estimated from a general circulation model constrained by World Ocean Circulation Experiment (WOCE) data. J. Geophys. Res., 108, 3007, doi:10.1029/2001JC001115.

Thurnherr, A. M., L. C. St. Laurent, K. G. Speer, J. M. Toole, and J. R. Ledwell, 2005: Mixing associated with sills in a canyon on the midocean ridge flank. J. Phys. Oceanogr., 35, 13701381.

Toole, J. M., and B. A. Warren, 1993: A hydrographic section across the subtropical south Indian Ocean. Deep-Sea Res. I, 40, 1973-2019.

Warren, B. A., and G. C. Johnson, 2002: The overflows across the Ninetyeast Ridge. Deep-Sea Res. II, 49, 1423-1439.

Wunsch, C., and R. Ferrari, 2004: Vertical mixing, energy, and the general circulation of the oceans. Annu. Rev. Fluid Mech., 36, 281-314.

Zhang, K. Q., and J. Marotzke, 1999: The importance of openboundary estimation for an Indian Ocean GCM-data synthesis. J. Mar. Res., 57, 305-334. 